\title{
Regional CO pollution and export in China simulated by the high-resolution nested-grid GEOS-Chem model
}

\author{
D. Chen ${ }^{1}$, Y. Wang ${ }^{1,2}$, M. B. McElroy ${ }^{2}$, K. He ${ }^{1}$, R. M. Yantosca ${ }^{2}$, and P. Le Sager ${ }^{2}$ \\ ${ }^{1}$ Department of Environmental Science and Engineering, Tsinghua University, Beijing, China \\ ${ }^{2}$ Division of Engineering and Applied Sciences and Department of Earth and Planetary Sciences, Harvard University, \\ Cambridge, Massachusetts, USA
}

Received: 4 January 2009 - Published in Atmos. Chem. Phys. Discuss.: 4 March 2009

Revised: 29 May 2009 - Accepted: 2 June 2009 - Published: 12 June 2009

\begin{abstract}
An updated version of the nested-grid GEOSChem model is developed allowing for higher horizontal $\left(0.5^{\circ} \times 0.667^{\circ}\right)$ resolution as compared to global models. $\mathrm{CO}$ transport over a heavily polluted region, the Beijing-TianjinHebei (BTH) city cluster in China, and the pattern of outflow from East China in summertime are investigated. Comparison of the nested-grid with global models indicates that the fine-resolution nested-grid model is capable of resolving individual cities with high associated emission intensities. The nested-grid model indicates the presence of a high $\mathrm{CO}$ column density over the Sichuan Basin in summer, attributable to the low-level stationary vortex associated with the Basin's topographical features. The nested-grid model provides good agreement also with measurements from a suburban monitoring site in Beijing during summer 2005. Tagged CO simulation results suggest that regional emissions make significant contributions to elevated CO levels over Beijing on polluted days and that the southeastward moving cyclones bringing northwest winds to Beijing are the key meteorological mechanisms responsible for dispersion of pollution over Beijing in summer. Overall CO fluxes to the NW Pacific from Asia are found to decrease by a factor of 3-4 from spring to summer. Much of the seasonal change is driven by decreasing fluxes from India and Southeast Asia in summer, while fluxes from East China are only 30\% lower in summer than in spring. Compared to spring, summertime outflow from Chinese source regions is strongest at higher latitudes (north of $35^{\circ} \mathrm{N}$ ). The deeper convection in summer transporting $\mathrm{CO}$ to higher altitudes where export is more efficient is largely responsible for enhanced export in summer.
\end{abstract}

Correspondence to: $\mathrm{K}$. $\mathrm{He}$

(hekb@tsinghua.edu.cn)

\section{Introduction}

Chemical transport models are effective in simulating the combined influences of physical and chemical processes affecting the distribution of a key chemical species in the Earth's atmosphere. The domain of an atmospheric model varies from hundreds of meters to thousands of kilometers (Seinfeld and Pandis, 1998). Global climate change or stratospheric ozone depletion is simulated over a global scale domain and over periods ranging from months to hundreds of years and beyond. Specific air pollution issues such as acid deposition and long-range transport of particulates and ozone are simulated over synoptic to global-scale domains over periods of days to months. Urban air pollution is simulated over micro- to mesoscale domains over periods ranging from hours to days. It is impossible to simulate the variation of species concentrations at scales smaller than the model resolution. For example, a global scale model that treats the entire area as one computational cell of uniform chemical composition cannot describe the spatial variations in pollution levels across the two adjacent large Chinese cities of Beijing and Tianjin.

The diffusion equation in regional atmospheric models needs side boundary conditions in the $x, y$, and $z$ directions, whereas global models simulate the Earth's atmosphere as a whole. It is difficult to obtain exact values of tracer concentrations for all points of the side boundaries as a function of time. Boundary conditions, especially at the upwind boundaries, continue to affect model predictions throughout the simulation. Song et al. (2008) used the simulation results of a global chemistry model, the Real-time Air Quality Modeling System (RAQMS), to provide dynamic lateral boundary conditions for regional air quality simulations using the Models-3 Community Multiscale Air Quality (CMAQ) Model. They found that use of the dynamic

Published by Copernicus Publications on behalf of the European Geosciences Union. 
boundary conditions not only improved CMAQ's simulations of diurnal variations resolving the daily maxima of surface $\mathrm{O}_{3}$ but resulted also in better agreement with the vertical structure of $\mathrm{O}_{3}$ measured in the middle and upper troposphere. Compared to the simulation with predefined lateral boundary condition profiles, it is suggested that at the upper troposphere more than $85 \%$ of the $\mathrm{O}_{3}$ concentration difference associated with the lateral boundary conditions was caused by the transport and diffusion processes. The regional and global models employed in their study, however, used different meteorological fields, employed different chemical mechanisms, and also differed in their treatments of transport. Wang et al. (2004a) developed a one-way nestedgrid capability in the global GEOS-Chem model based on GEOS-3 meteorology. The nested-grid formulation included a regional window with relatively high spatial resolution $\left(1^{\circ}\right.$ (latitude) $\times 1^{\circ}$ (longitude)) embedded in a lower-resolution global context $\left(4^{\circ} \times 5^{\circ}\right)$ of the GEOS-Chem model. Results from the coarse global model simulation were used to drive the nested-grid model through time-varying boundary conditions. The high-resolution, nested-grid simulation employed the same meteorology, dynamics, and chemistry as the global GEOS-Chem model, thus allows for consistent propagation of features into the domain. Through detailed analysis of improvements in $\mathrm{CO}$ simulations that were simply the consequences of increasing the spatial resolutions, Wang et al. (2004a) found that the higher-resolution model allowed for more efficient, advection-related ventilation of the lower atmosphere, reflecting the significance of localized regions of intense upward motion not resolved in the coarserresolution simulation. The nested-grid GEOS-Chem model has been employed in a variety of applications for East Asia (Wang et al., 2004a, 2004b), North America (Fiore et al., 2006; Li et al., 2006; Park et al., 2006), and Europe. However, even the higher resolution of $1^{\circ} \times 1^{\circ}$ is still too coarse to address concerns relating to regional-scale air quality over complex terrains or in regions characterized by complex patterns of emissions.

This work follows the methodology of Wang et al. (2004a) to develop an updated version of the nested-grid capability in the global GEOS-Chem model (Bey et al., 2001) using the newest version of GEOS-assimilated meteorological data (GEOS-5), which allows for higher spatial resolutions over the nested domain. Compared to the original version of the nested-grid GEOS-Chem model designed for GEOS-3 meteorology with a horizontal resolution of $1^{\circ} \times 1^{\circ}$ and 10 sigma levels below $2 \mathrm{~km}$, the GEOS- 5 meteorology allows for spatial resolutions of $0.5^{\circ} \times 0.667^{\circ}$ with 15 hybrid eta levels below $2 \mathrm{~km}$ for the nested domain. The horizontal and vertical resolution of the GEOS-5 nested-grid model is comparable to that of many regional-scale models. For purpose of this application the nested domain with high resolution $\left(0.5^{\circ} \times 0.667^{\circ}\right)$ is set over East Asia, where rapid economic growth in recent years has resulted in large increases in pollutant emissions with implications for the global environment.
The nested-grid capability can be easily adopted for other regions of the globe (Fiore et al., 2005; Li et al., 2005).

This work focuses on summertime transport of pollutants over a particular region of China, the Beijing-Tianjin-Hebei (BTH) city cluster. The emission distributions for this area are illustrated in Fig. 1. Consisting of only $2.3 \%$ of China's land area, the BTH city cluster accounts for $10.5 \%$ of China's $\mathrm{SO}_{2}$ emissions and $10.9 \%$ of its $\mathrm{NO}_{x}$ emissions (Zhang et al., 2009). Taking advantage of the increased horizontal resolution of $0.5^{\circ} \times 0.667^{\circ}$ roughly $40 \mathrm{~km} \times 50 \mathrm{~km}$ over China), it is possible for the nested-grid GEOS-Chem model to resolve the heterogeneous transport and emission patterns over the BTH city cluster. $\mathrm{CO}$ is used as a convenient tracer to indicate the frequency and magnitude of influences from vehicle emissions and other combustion sources related to urban pollution.

Many previous studies have examined the mechanisms controlling the outflow of CO from Asia to the NW Pacific in springtime, the season with maximum export fluxes (Liu et al., 2003; Fuelberg et al., 2003; Liang et al., 2004, 2005, 2007; Miyazaki et al., 2003; Koile et al., 2003; Holzer et al., 2005). Liang et al. (2004, 2005, 2007) and Koile et al. (2003) have studied the pollution and outflow from East Asia in summertime. However, all these studies took China or East Asia as a whole, whereas there exits significant regional differences within East Asia and China in terms of meteorology and emission characteristics. The present study will examine the outflow pattern and efficiencies for export of $\mathrm{CO}$ from different administrative regions of China, focusing also on seasonal differences between spring and summer.

The nested-grid approach adopted here is described in Sect. 2. The high-resolution nested-grid simulation is evaluated in Sect. 3 comparing the present results with surface observations and with results from the coarse resolution model. The nested-grid model is employed in Sect. 4 to examine the meteorological conditions regulating day-to-day variations in $\mathrm{CO}$ at a suburban site in Beijing. Tagged CO simulations were conducted to estimate the contributions of local and regional emissions to CO levels over Beijing. In Sect. 5, we compare the outflow pattern and export efficiencies of $\mathrm{CO}$ from China between spring and summer. Concluding remarks are presented in Sect. 6 .

\section{Modeling approach}

\subsection{Nested grid formulation}

The GEOS-Chem global 3-D model for tropospheric chemistry is driven by meteorological data assimilated by the Goddard Earth Observing System (GEOS) at the NASA Global Modeling and Assimilation Office (GMAO) (Bey et al., 2001). The GEOS assimilated meteorology has gone through many versions over the past ten years, evolving from GEOS1 to the most recent version of GEOS-5. The present study 
$\begin{array}{ll}\text { (a) } 0.5^{\circ} \times 0.667^{\circ} & \text { (b) } 0.5^{\circ} \times 0.667^{\circ}\end{array}$

(China)

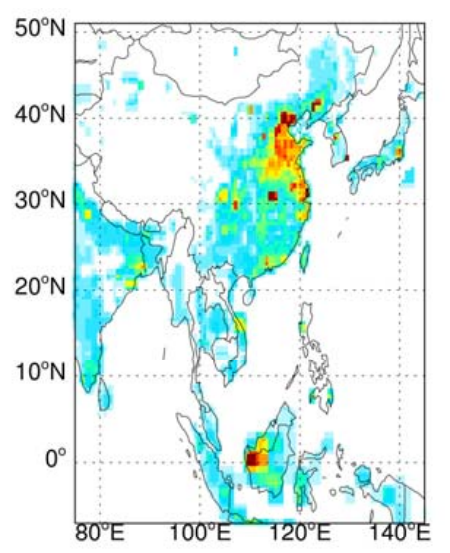

(Beijing- Tianjin-Hebei Region)

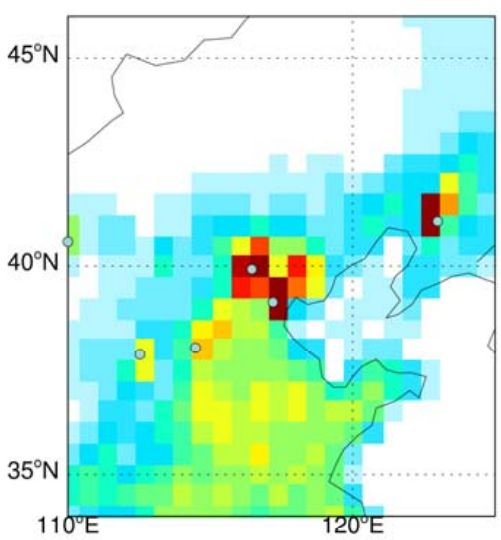

(c) $2^{\circ} \times 2.5^{\circ}$

(Beijing- Tianjin-Hebei Region)

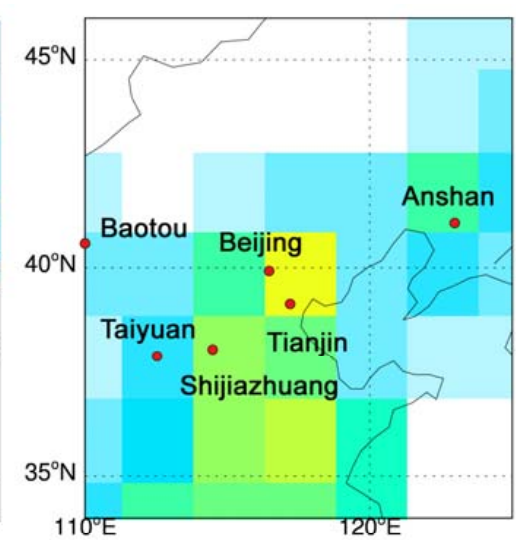

[g/m2/month]

Fig. 1. (a-c) Total CO emissions for China and the Beijing-Tianjin-Hebei Region, (a) $0.5^{\circ} \times 0.667^{\circ}$ (China), (b) $0.5^{\circ} \times 0.667^{\circ}$ (BeijingTianjin-Hebei Region), (c) $2^{\circ} \times 2.5^{\circ}$ (Beijing- Tianjin-Hebei Region). Units are in $\mathrm{g} / \mathrm{m}^{2} / \mathrm{month}$. Geophysical locations of capital cities in the region are illustrated in panel (c).

used GEOS-5 meteorology extending from December 2004 to present. We chose in this application to use GEOS-Chem version 8-01-01 (http://www.as.harvard.edu/chemistry/trop/ geos), the first version of GEOS-Chem that is fully compatible with the GMAO GEOS-5 operational meteorology data. Meteorology fields in the GEOS-5 data have a temporal resolution of $6 \mathrm{~h}$ ( $3 \mathrm{~h}$ for surface variables and mixing depths) and a horizontal resolution of $0.5^{\circ}$ latitude by $0.667^{\circ}$ longitude, with 72 hybrid eta levels in the vertical column that extending from the surface to $0.01 \mathrm{hPa}$. The lowest $2 \mathrm{~km}$ is resolved by 14 layers with midpoints at altitudes of 70, 200, 330, 470, $600,740,880,1000,1160,1300,1440,1600,2000 \mathrm{~m}$ for a column based at sea level. Details of this data source are presented elsewhere (Rienecker et al., 2007). For inputs to the global GEOS-Chem model, the horizontal resolution of the meteorological fields is degraded to $2^{\circ}$ latitude $\times 2.5^{\circ}$ longitude or $4^{\circ}$ latitude $\times 5^{\circ}$ longitude due to computational limitations. Details of the degradation process are provided by Wang et al. (2004a). Compared to the global GEOS-Chem model, the nested-grid GEOS-Chem model retains the native high horizontal resolution over the nested regional domain.

The GEOS-5 meteorology uses an advection code different from that of GEOS-3, partly because different vertical coordinates were used in the two versions of GEOS assimilated meteorology. Lateral boundary conditions for the nested-grid model were added in the GEOS-5 advection code following the same methodology of Wang et al. (2004a). The nested regional domain $\left(70^{\circ} \mathrm{E}-150^{\circ} \mathrm{E}, 11^{\circ} \mathrm{S}-55^{\circ} \mathrm{N}\right.$; cf. Fig. 1 in Wang et al., 2004a) includes all of China, its neighboring countries (stretching from Pakistan in the west to Japan in the east and from Indonesia in the south to Mongolia in the north), and a significant portion of the northwestern Pacific. The high resolution regional domain is nested into a global domain treated with a resolution of $4^{\circ} \times 5^{\circ}$. The outermost grids at the lateral boundaries of the high-resolution nestedgrid domain were used to delineate a buffer zone separating low and high-resolution portions of the model (Wang et al., 2004a). To provide boundary conditions for the regional model, the global assimilation was run at the spatial resolution of 4 degrees latitude by 5 degrees longitude. The tracer mixing ratios for the buffer zone grids were saved for every three hours consistent with the temporal resolution of the meteorology data. The archived, time-varying boundary conditions were used to drive high-resolution nested-grid model runs.

\subsection{CO simulation}

A CO-only simulation was conducted using the global model with its higher resolution nested-grid for summer 2005 with specified $\mathrm{OH}$ fields derived from a global coupled $\mathrm{NO}_{x^{-}}$ VOCs- ${ }_{3}$-aerosol simulation (Wang et al., 2004a). The global simulation was conducted first at $4^{\circ} \times 5^{\circ}$ resolution (referred to as the coarse-resolution global model) and then at $2^{\circ} \times 2.5^{\circ}$ resolution (referred to as the intermediateresolution global model). To avoid transients associated with initial conditions, the coarse-resolution global model was run for one month beginning on 1 December 2004. Results for 
1 January 2005 were saved and interpolated onto the $2^{\circ} \times 2.5^{\circ}$ and $0.5^{\circ} \times 0.667^{\circ}$ grids providing initial conditions for the intermediate global model and the associated high-resolution nested-grid. Simulations with different resolutions were conducted for the period from January to September 2005. Boundary conditions for the nested-grid model were provided by the coarse-resolution global model (i.e., $4^{\circ} \times 5^{\circ}$ resolution). Results were presented for July to September 2005, allowing sufficient time for the high-resolution model to adjust to transients introduced by the initialization of the model on 1 January 2005.

In Sect. 3, we examine the differences relating to the higher spatial resolution available in the nested-grid regional domain by comparing high-resolution nested-grid model outputs with the intermediate-resolution global simulation. Since the simulations with different resolutions adopted the same $\mathrm{OH}$ fields, differences in modeling $\mathrm{CO}$ may be entirely attributed to the higher resolution specification of sources and to differences in the treatment of transport as simulated using the one-way nested formulation.

\subsection{CO emissions}

Anthropogenic emissions of $\mathrm{CO}$ from the combustion of fossil fuel and biofuel over the nested East Asia domain were taken from Zhang et al. (2009) for the year 2006. A series of improved methodologies were implemented in the study of Zhang et al. (2009) to gain a better understanding of emissions from China, including a detailed technologybased approach, a dynamic methodology representing rapid technology renewal and critical examination of energy statistics. The inventory was based upon the studies of Streets et al. (2006), which improved estimations for emissions from Chinese industrial sources that had been underestimated in the inventory developed earlier in support of the TRACE-P aircraft mission (Streets et al., 2003). Zhang et al. (2009) found that Chinese emissions of CO increased by $18 \%$ from 2001 to 2006. The anthropogenic CO emissions in 2006 from Asia and China used in the model are 298.2 and $166.9 \mathrm{Tg} /$ year respectively, with no month-to-month variations. The updated inventory was downloaded from http: $/ /$ mic.greenresource.cn/intex-b2006 at $0.5^{\circ} \times 0.5^{\circ}$ resolution . The $0.5^{\circ} \times 0.5^{\circ}$ gridded emission inventory was degraded into $4^{\circ} \times 5^{\circ}, 2^{\circ} \times 2.5^{\circ}, 0.5^{\circ} \times 0.667^{\circ}$ using spatial averaging.

For emissions associated with fossil fuels over the rest of the world, we adopted inventories reported by Duncan et al. (2003). Emissions due to the combustion of biofuel and the burning of biomass were taken from Yevich and Logan (2003) and Duncan et al. (2003), respectively. These emissions were defined with respect to a $1^{\circ} \times 1^{\circ}$ grid. The $1^{\circ} \times 1^{\circ}$ emissions data sets were regridded to match the $4^{\circ} \times 5^{\circ}, 2^{\circ} \times 2.5^{\circ}, 0.5^{\circ} \times 0.667^{\circ}$ model resolutions.

\section{Effect of model resolution on CO over Asia}

\subsection{Heterogeneity of $\mathrm{CO}$ emissions}

The spatial distribution of composite $\mathrm{CO}$ emissions over the nested domain is presented in Fig. 1a. The emission distribution in China shows the characteristics of the fossil fuel and biofuel combustions, spatially differentiated by economic development, industry structure, and population. At $0.5^{\circ} \times 0.667^{\circ}$ resolution, the inventory explicitly resolves contributions from several Chinese urban regions with high emission intensities (Zhang et al., 2009): a) cities with higher levels of urbanization and motorization, such as Beijing $\left(116.46^{\circ} \mathrm{E}, 39.92^{\circ} \mathrm{N}\right)$, Shanghai $\left(121.48^{\circ} \mathrm{E}, 31.22^{\circ} \mathrm{N}\right)$, and Guangzhou $\left(113.23^{\circ} \mathrm{E}, 23.16^{\circ} \mathrm{N}\right)$, where the transportation sector contributes $40-60 \%$ of $\mathrm{CO}$ emissions, b) cities such as Anshan $\left(123.00^{\circ} \mathrm{E}, 41.8^{\circ} \mathrm{N}\right)$, Shijiazhuang $\left(114.48^{\circ} \mathrm{E}\right.$, $\left.38.03^{\circ} \mathrm{N}\right)$, and Taiyuan $\left(112.53^{\circ} \mathrm{E}, 37.87^{\circ} \mathrm{N}\right)$, with heavy industrial manufacturing where industrial sources contribute more than $40 \%$ of total emissions, and c) densely populated such as Chongqing $\left(106.54^{\circ} \mathrm{E}, 29.59^{\circ} \mathrm{N}\right)$, Tianjin $\left(117.2^{\circ} \mathrm{E}\right.$, $\left.39.1^{\circ} \mathrm{N}\right)$, and Wuhan $\left(114.31^{\circ} \mathrm{E}, 30.52^{\circ} \mathrm{N}\right)$, cities with multiple sources. Most of these cities can be identified in Fig. 1a as individual "hot" spots, while Beijing, Tianjin, and Shijiazhuang are located so close together as to merge into one, large region with high emissions.

The ability of the high-resolution nested-grid model to resolve the heterogeneity of emissions over the BeijingTianjin-Hebei (BTH) city cluster is illustrated in Fig. 1b. For comparison, Fig. 1c shows emissions for the same region at $2^{\circ} \times 2.5^{\circ}$ resolution. The emission data at $0.5^{\circ} \times 0.667^{\circ}$ resolution resolve the differences in emission intensities in individual cities, whereas Beijing, Tianjin, and a part of Hebei province are aggregated in the $2^{\circ} \times 2.5^{\circ}$ description. The increase of model resolutions from $2^{\circ} \times 2.5^{\circ}$ to $0.5^{\circ} \times 0.667^{\circ}$ enhanced the ability of the model to represent emissions at the scale of individual cities, although the $0.5^{\circ} \times 0.667^{\circ}$ resolution is still not fine enough to capture spatial variations in emissions within a particular city.

\subsection{CO mixing ratios}

In this section, we evaluate the spatial patterns in $\mathrm{CO}$ simulated by the nested-grid model by comparing tropospheric CO columns between model results and MOPITT satellite retrievals. MOPITT data used here are Level-3 monthly averaged daytime (10:00-12:00 local time) CO columns at $1^{\circ} \times 1^{\circ}$ resolution (http://www.acd.ucar.edu/mopitt/products.shtml). Daily model outputs sampled at the same time of MOPITT overpasses are processed and averaged at the same resolution as MOPITT. Spatial distributions of daytime tropospheric CO columns for August 2005 are presented in Fig. 2. The figure includes results from the high-resolution nestedgrid model (Fig. 2a), the intermediate-resolution global model (Fig. 2b) and MOPITT (Fig. 2c). Results from the 
(a) $0.5 \times 0.667$

(b) $2 \times 2.5$

(c) MOPITT

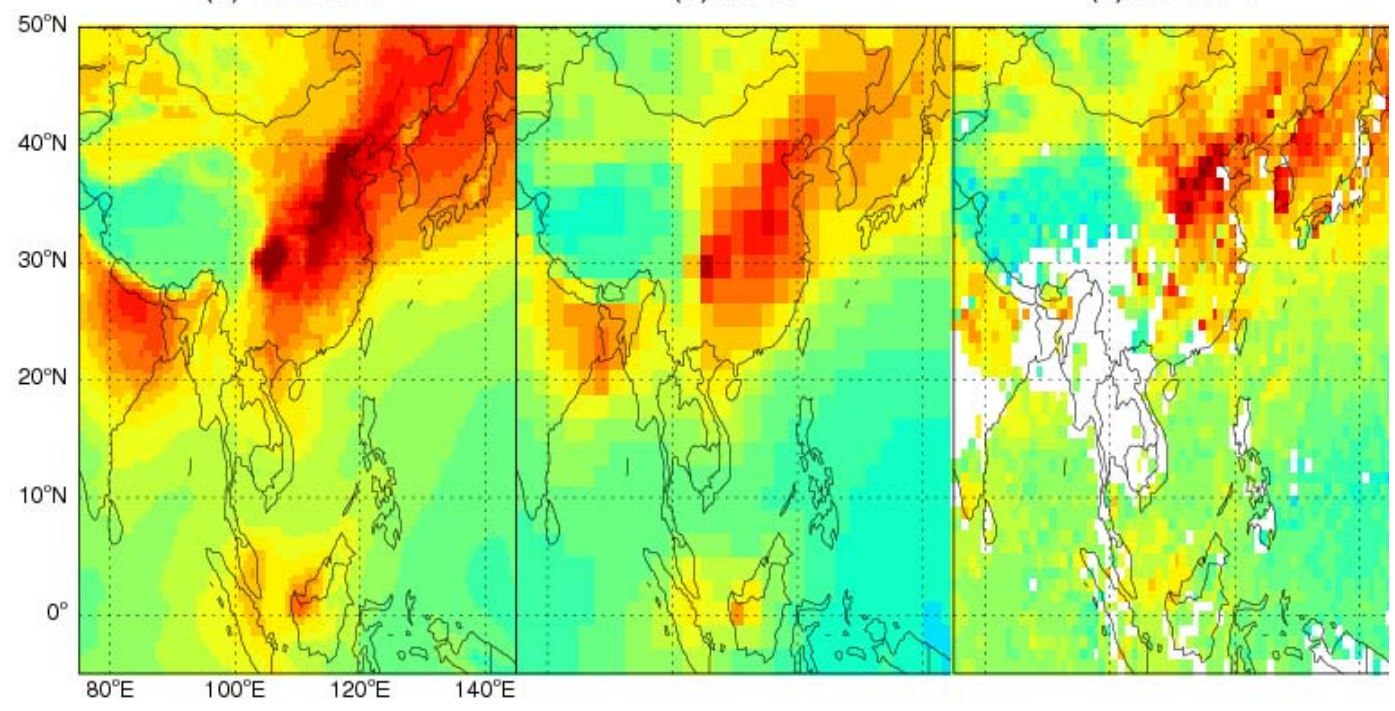

$[\mathrm{E}+18 \mathrm{molec} / \mathrm{cm} 2]$

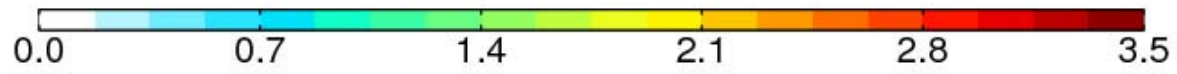

Fig. 2. Comparisons of CO Daytime total column for August 2005 , simulated by (a) the fine-resolution $\left(0.5^{\circ} \times 0.667^{\circ}\right)$, (b) intermediateresolution $\left(2^{\circ} \times 2.5^{\circ}\right)$, (c) MOPITT.

coarse-resolution global model $\left(4^{\circ} \times 5^{\circ}\right)$ are similar to those from the intermediate-resolution model $\left(2^{\circ} \times 2.5^{\circ}\right)$ and are not included. Spatial patterns of the two models are similar to those retrieved by MOPITT, with high column densities in regions of high anthropogenic emissions, notably central and eastern China. The correlate coefficients are about 0.9 between MOPITT and models of $0.5^{\circ} \times 0.667^{\circ}$ or $2^{\circ} \times 2.5^{\circ}$ resolutions. However, the higher resolution simulation produces stronger gradients over the Asia region with spatially varying emissions, in particular over the North China Plain, more consistent with the MOPITT data.

Spatial distributions of surface $\mathrm{CO}$ mixing ratios are presented in Fig. 3a-b. Spatial patterns are similar for the two models, reflecting emission characteristics with the highest concentrations in Kalimantan Island, South Asia, notable for its regions of high biomass burning. High mixing ratios of $\mathrm{CO}$ are found for the Bejing-Tianjin-Hebei region, central and eastern China, and the Sichuan Basin. At $0.5^{\circ} \times 0.667^{\circ}$ resolution, the individual grids with high mixing ratios (Fig. 3a) can be easily mapped to the locations of the cities with high emissions as indicated in Fig. 1b, illustrating a clear contrast with surrounding grids that have relatively low $\mathrm{CO}$. At $2^{\circ} \times 2.5^{\circ}$ resolution, however, emissions from these cities are smeared out to a larger area, resulting in lower concentrations in cities, compensated by higher concentrations in surrounding grids.

\subsection{Sichuan Bain low-level vortex}

It is interesting to note that the $\mathrm{CO}$ daytime total columns displays a distinct peak over the Sichuan Basin the dark regions centered at $\left(105^{\circ} \mathrm{E}, 30^{\circ} \mathrm{N}\right)$ in Fig. 2 in the high-resolution nested-grid model, but the peak is not so obvious in the intermediate global model. The terrain elevations, winds and surface pressure for the Tibetan Plateau- Sichuan Basin Area are presented in Fig. 4. Figure 4a displays the terrain elevations at a resolution of 3 arc-minute (http://www.ngdc.noaa. gov/mgg/topo/pictures/GLOBALeb3colshade.jpg), illustrating the rapid change in elevation from the Tibetan Plateau (4-5 km elevation) and Yunan-Guizhou Plateau (2-3 km elevation) to the Sichuan Basin (0.5 km elevation). As shown in Fig. 4a, the Sichuan Basin locates in the center between the Tibetan Plateau and Yunnan-Guizhou Plateau, making it a saddle pattern for topography. Figure $4 \mathrm{~b}-\mathrm{c}$ are the winds at $2 \mathrm{~km}$ overlaid with surface pressure simulated by the model at $0.5^{\circ} \times 0.667^{\circ}$ (b) and $2^{\circ} \times 2.5^{\circ}$ resolutions (c). In summer, influenced by the southwesterly East Asian summer monsoon, winds blow in a cyclonic pattern over the southeast part of the Sichuan basin. The Tibetan High formed over the middle part of the Tibetan Plateau as the western Pacific Subtropical High shifted westward to the west of the Sichuan Basin (Chen, et al., 2007). Figure $4 \mathrm{~b}$ clearly shows the pattern described above. Under the influence of the large scale circulations, strong northwesterly flow enters the basin 
(a) $0.5 \times 0.667$

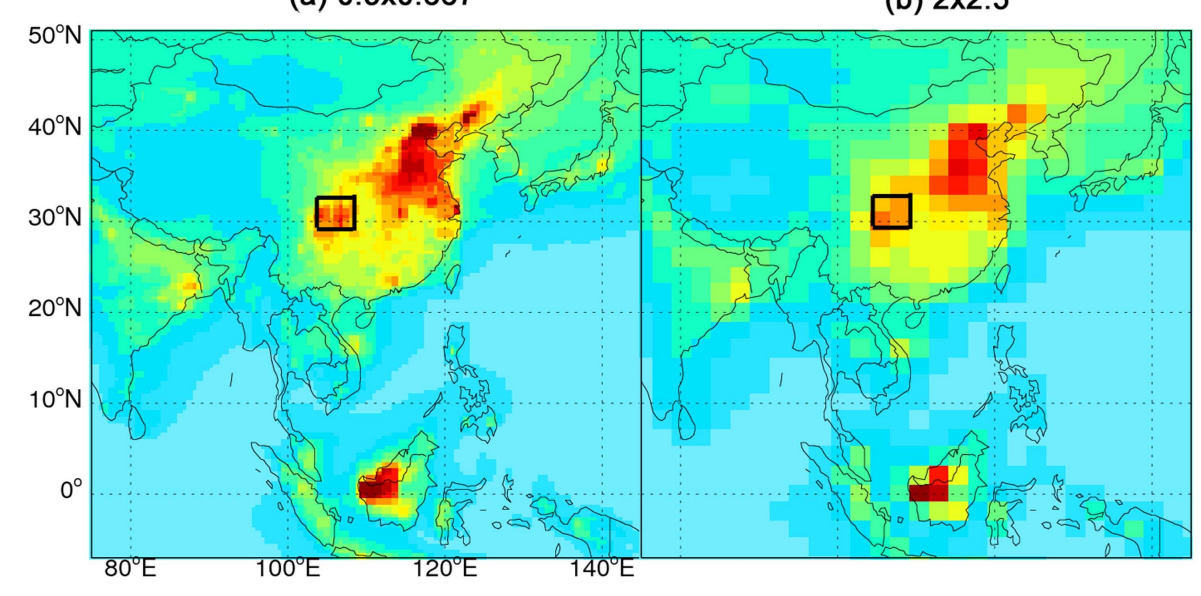

Fig. 3. Comparisons of CO mixing ratios averaged in surface for August 2005 , simulated by (a) the fine-resolution $\left(0.5^{\circ} \times 0.667^{\circ}\right),(\mathbf{b})$ the intermediate-resolution $\left(2^{\circ} \times 2.5^{\circ}\right)$.

around the east edge of the Tibetan Plateau, while southwesterly flow enters the eastern part of the Sichuan Basin around the northwest edge of the Yunnan-Guizhou Plateau. The interaction between the two flows forms a convergent zone of northward jet stream over the east of the Sichuan Basin due to the blocking effect of topography and the westward shift of the Western Pacific Subtropical High. Chen et al. (2007) also found that since dry air continuously entered the upper level over the Sichuan basin, strong instability of vertical convection formed over the basin and developed toward the northeast of the basin, which maintained and continuously intensified cyclonic vorticity. The process makes the Sichuan Basin a favorable location for stationary low-level vortices, or the so-called the Southwest Vortex (Chang et al., 2002), which tend to trap pollutants within the columns above the Basin. As shown in Fig. 4c, the resolution of the intermediate global model is too coarse to resolve the terrain effects of the Basin and the meteorological features accordingly.

\subsection{Differences between urban and suburban grids}

We examine in this section the extent to which the nestedgrid model with its current $0.5^{\circ} \times 0.667^{\circ}$ resolution can differentiate between urban and suburban areas with different emission intensities. The intermediate global model is used for comparison. We focus on the BTH city cluster, one of the most populous and polluted regions in China. The surface $\mathrm{CO}$ mixing ratio simulated by the nested-grid model and the intermediate global model for this region is displayed in detail in Fig. 5a-b, respectively. Two adjacent grids over Beijing with available $\mathrm{CO}$ observations, an urban grid (center $116.67^{\circ} \mathrm{E}, 40.00^{\circ} \mathrm{N}$ ) and a suburban grid (Dingling, DL for short, grid center $116.00^{\circ} \mathrm{E}, 40.00^{\circ} \mathrm{N}$ ), were chosen for comparison. Their locations are shown in an administrative map of Beijing in Fig. 5c. Within the urban grid, there are six monitoring sites covering commercial, residential, and transportation environments. The suburban grid has only one surface station, DL $\left(116.2^{\circ} \mathrm{E}, 40.22^{\circ} \mathrm{N}\right)$, located $42 \mathrm{~km}$ northwest of Beijing's urban center. Hourly observations of $\mathrm{CO}$ mixing ratios at the seven sites within the two grids were collected by the Beijing Municipal Environmental Monitoring Center.

Beijing is situated at the northern tip of the roughly triangular North China Plain with a northwest high and a southeast low as its primary topographical features. The northern part is dominated by the Yanshan and Taihang Mountains, which intersect and form a semicircle called the "Beijing Bend." Another large city, Tianjin Municipality (population of about 10 million) is located $150 \mathrm{~km}$ southeast of Beijing. The terrain around Tianjin is generally flat and swampy near the coast and hilly in the far north. The climate of the BTH region in summertime is influenced by the East Asian summer monsoon with prevailing southwest winds at the surface.

The monthly mean mixing ratios of CO during three months (July, August, and September) in 2005 are summarized in Table 1, including both observations and model results for comparison. The data are represented as daily ( $24 \mathrm{~h})$ and daytime (10:00-18:00) averages. The monthly mean (both daily and daytime means) mixing ratios of $\mathrm{CO}$ as simulated by the $0.5^{\circ} \times 0.667^{\circ}$ nested-grid model for both the urban grid and suburban grid are higher than the values derived using the intermediate global model and in better agreement with the observations. Due to resolution limitations, the 
Table 1. Average CO mixing ratios for July-August-September 2005 (unit: ppbv).

\begin{tabular}{cccccc}
\hline \multicolumn{3}{c}{ Suburban DL } & \multicolumn{3}{c}{ Urban Beijing } \\
\hline Observations & $0.5^{\circ} \times 0.667^{\circ}$ & $2^{\circ} \times 2.5^{\circ}$ & observations & $0.5^{\circ} \times 0.667^{\circ}$ & $2^{\circ} \times 2.5^{\circ}$ \\
& model & model & & model & model \\
802 & 710 & 486 & 1296 & 791 & 594 \\
\hline
\end{tabular}

urban grid in the intermediate global model $\left(2^{\circ} \times 2.5^{\circ}\right.$ resolution) includes not only the Beijing area, but also Tianjian and a great part of Hebei province, while the suburban grid includes a large part of rural Beijing and Hebei. Here we compare the grid-averaged model results with point observations close to high emission areas (i.e. Beijing), where the smaller the model grid, the less diluted the emissions from Beijing and thus the higher the $\mathrm{CO}$ concentrations predicted by the model. The table clearly attests to the improvement in the simulation obtained by increasing the model resolution from $2^{\circ} \times 2.5^{\circ}$ to $0.5^{\circ} \times 0.667^{\circ}$, as indicated by comparison of results in Fig. 5a-b.

Compared with the observation, concentrations derived using the $0.5^{\circ} \times 0.667^{\circ}$ model are still too low for both the urban and the suburban DL grids. The modeled mixing ratios at the urban Beijing grid and the suburban DL grid are 39\% and $11 \%$ lower than the observations. The underestimates of daily mean mixing ratios by the model may be partly due to underestimates of $\mathrm{CO}$ emissions as inventory estimates for Chinese $\mathrm{CO}$ emissions are still uncertain (Zhang et al., 2009). More importantly, the six monitoring sites within the urban grid are all located within a $10 \mathrm{~km}$ range of the city center, while the urban emissions as simulated in the nestedgrid model, even given its relative high applied resolution $\left(0.5^{\circ} \times 0.667^{\circ}\right)$ are much more diluted.

\section{A case study: summertime $\mathrm{CO}$ variations in Beijing}

To investigate the meteorological factors responsible for the alternations between heavy pollution days and clean days in the BTH region in summertime, we first compared the modeled and observed time series of $\mathrm{CO}$ mixing ratios and related meteorological parameters for July 2005 at the DL site. The reason for focusing on the suburban DL site rather than on the urban site is because the resolution limitation of the nestedgrid model made it impossible to simulate the very high $\mathrm{CO}$ levels at the urban site as indicated above.

\subsection{Day-to-day variations in $\mathrm{CO}$ and meteorology}

Time series of CO daily mixing ratios observed at the urban site and the suburban DL site are summarized in Fig. 6a. As discussed, the DL site was readily impacted by plumes with high levels of $\mathrm{CO}$ from the urban grid during the daytime, resulting in high temporal correlations between $\mathrm{CO}$ observations at the two sites $(\mathrm{r}=0.82)$. Given the nestedgrid model resolution, it was difficult for the model to simulate the exact timing and locations of the urban plume. To examine whether increasing spatial resolutions improves the model's ability to capture the variability, the percentage anomalies from the mean $\mathrm{CO}$ for observation and model are compared in Fig. 6b. The Figure includes results from the high-resolution nested-grid model and the intermediateresolution global model. When the observed $\mathrm{CO}$ levels are lower than $1500 \mathrm{ppbv}$, the high-resolution nested-grid model performs better than the global model in capturing the temporal variability of observations, such as for 3, 14 and 26 July. For other days with observed $\mathrm{CO}$ exceeding $1500 \mathrm{ppbv}$, the performance of the two models is almost the same in comparison to observations. The correlate coefficients between model and observations for July 2005 are 0.5 and 0.4 for the high-resolution and inter-mediate resolution simulations, respectively, while the correlate coefficients for the whole summer are around 0.60 for both models. The day-to-day variability of $\mathrm{CO}$ simulated by the models are generally weaker than observations, which is often the case when point measurements are compared with grid-averaged model predictions, since the DL site is frequently impacted by urban pollution plumes whose exact timing and scale are difficult to simulate at the spatial resolution of the nested-grid model. Other possible explanations for the bias of the model results include uncertainties in $\mathrm{CO}$ emissions (both in spatial and temporal distribution).

The comparisons of temperature and surface pressure between the model and observations are presented in Fig. $6 \mathrm{c}$. The data are for 14:00 local time in each day. The model reproduces the day-to-day variations in temperature and surface pressure. The correlation coefficients between model and observations are 0.87 for temperature and 0.98 for surface pressure. Figure $6 \mathrm{~d}$ compare model and observed values of daily wind speed at the surface. As the DL site may be influenced by local meteorology, the wind speeds here are the averaged results from not only DL sites but also the other 9 monitoring sites in this area. The correlation coefficient for wind speed was 0.62 for the whole month, with the model tending to overestimate wind speeds for most days. There were some cases where the model did a satisfactory job in simulating variations in both $\mathrm{CO}$ and wind speeds. For example, the relatively high mixing ratios of $\mathrm{CO}$ observed on 2 and 3 July were associated with relatively low wind speeds. 
(a) Terrain Elevations at 3 arc-minute grid

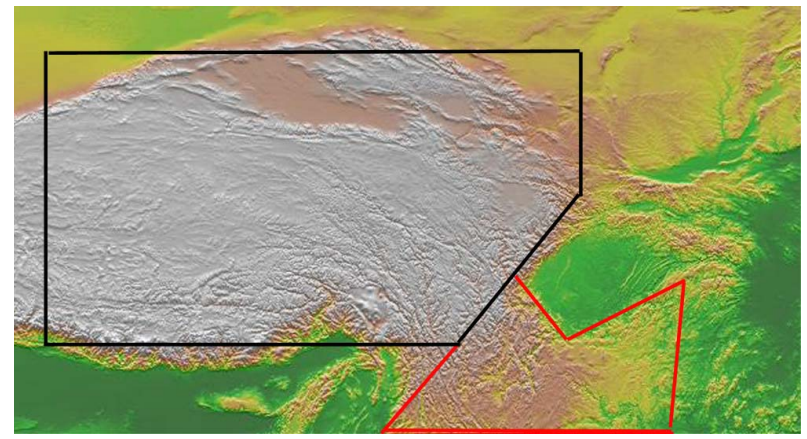

(b) Wind $(2 \mathrm{~km})$ and surface pressure $\left(0.5^{\circ} \times 0.667^{\circ}\right)$

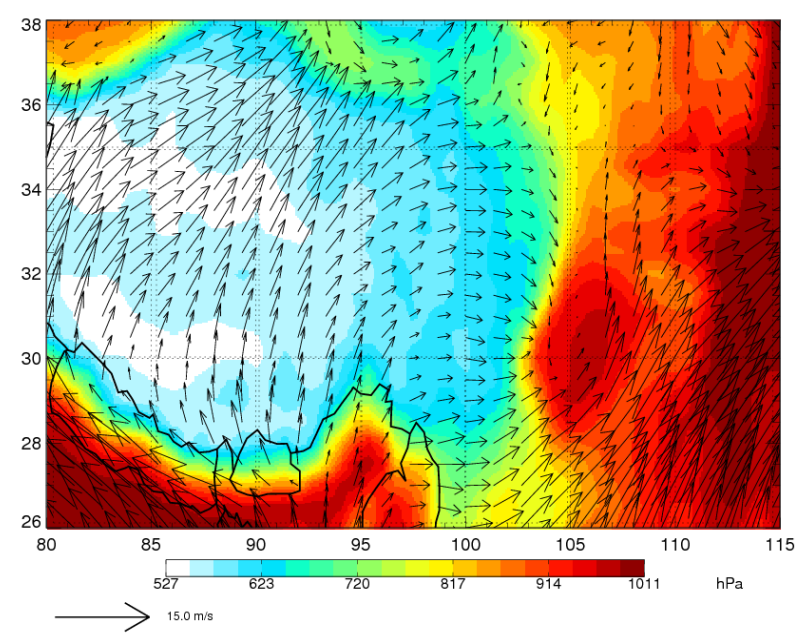

(c) Wind $(2 \mathrm{~km})$ and surface pressure $\left(2^{\circ} \times 2.5^{\circ}\right)$

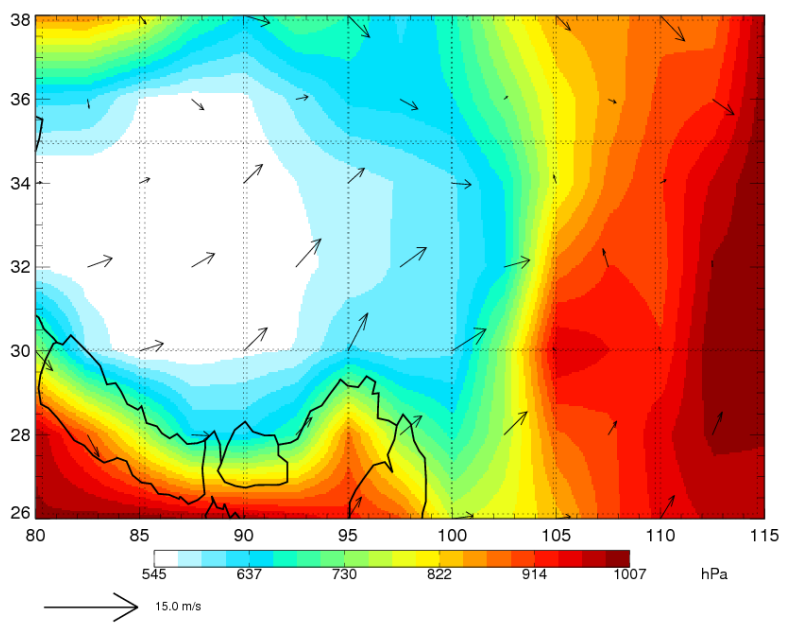

Fig. 4. Terrain elevations, winds and surface pressure of the Tibetan Plateau-Sichuan Basin Area in August 2005. (a) Terrain elevations at a resolution of 3 arc-minute (http://www.ngdc.noaa. gov/mgg/topo/pictures/GLOBALeb3colshade.jpg), the white area in black line is the Tibetan Plateau (Terrain elevation $\mathrm{H}=4-5 \mathrm{~km}$ ), the yellow area in red line is the Yunnan-Guizhou Plateau $(\mathrm{H}=2-$ $3 \mathrm{~km})$, the green area in circle is the Sichuan-basin $(\mathrm{H}=0.5-1 \mathrm{~km})$. (b) and (c) are the winds and surface pressures simulated by the $0.5^{\circ} \times 0.667^{\circ}$ and $2^{\circ} \times 2.5^{\circ}$ resolution respectively. (a) $0.5 \times 0.667$

(b) $2 \times 2.5$
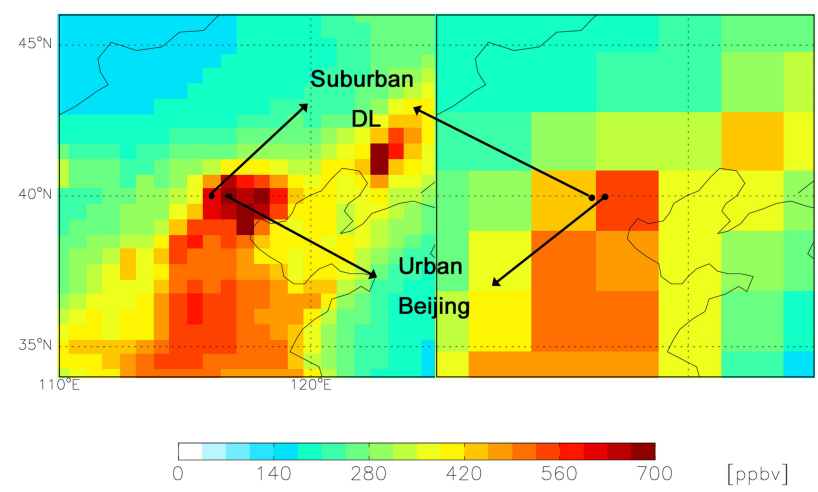

(c) Monitoring sites in Beijing

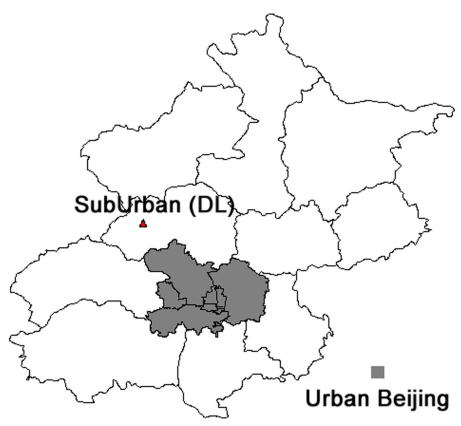

Fig. 5. Comparison of surface CO mixing ratio for August 2001 (Surface). (a) $0.5^{\circ} \times 0.667^{\circ}$. (b) $2^{\circ} \times 2.5^{\circ}$. Units are in ppbv. (c) Geophysical locations of monitoring sites in the region. The dark areas are eight urban districts of Beijing, and the light areas are the suburban districts, with DL site illustrated as a triangle.

The model reproduced the variability in $\mathrm{CO}$ and winds during these two days. The period of 25 and 26 July saw another successful simulation of $\mathrm{CO}$ and wind speeds by the model. But during 18-20 July, for example, the model overestimated wind speeds and underestimated $\mathrm{CO}$ mixing ratios to a large degree. Depending on local wind directions, the DL site may be influenced directly by urban emissions from Beijing or by regional pollution. If the DL site is under the strong influence of Beijing urban emissions, overestimates in wind speeds by the model may result in more rapid dilution and greater export of local emissions out of the grid, leading to the model's underestimates of $\mathrm{CO}$ mixing ratios at DL.

\subsection{Regional versus local influences}

To quantify the effects of different source regions on pollution levels over Beijing in summertime, we conducted a tagged CO simulation in which anthropogenic emissions of $\mathrm{CO}$ from the following seven Chinese regions were labeled and independently transported in the model: NEC (Northern East China), BJ (Beijing, consisting of only the urban grid 
(a) Daily CO concentrations at urban and DL sites for July 2005.

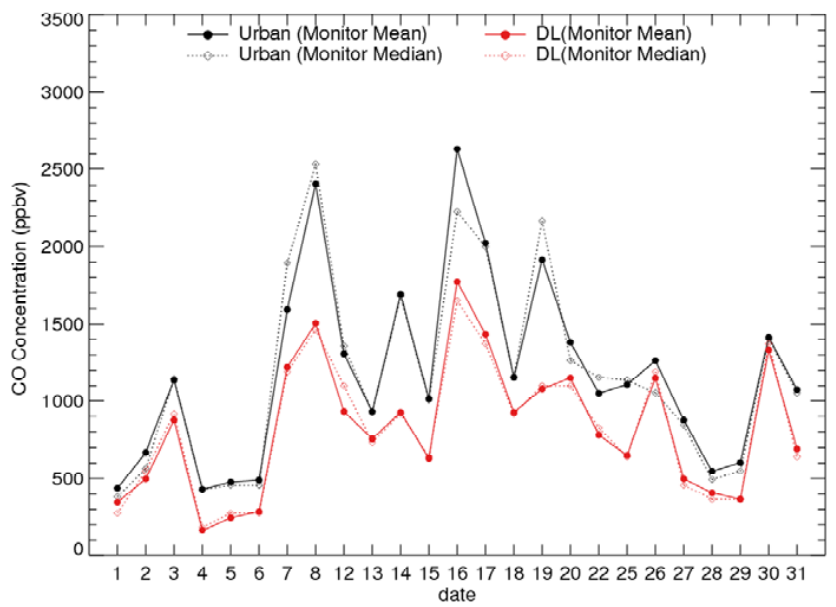

(c) Temperature and pressure for 14:00 at DL sites for July 2005.

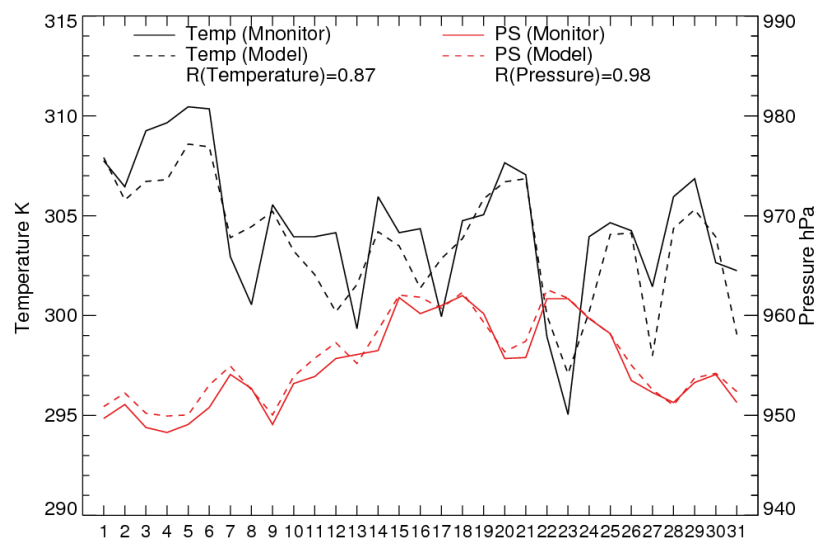

(b) Daily CO concentration variability in percentage anomalies from the mean CO at DL sites for July 2005.

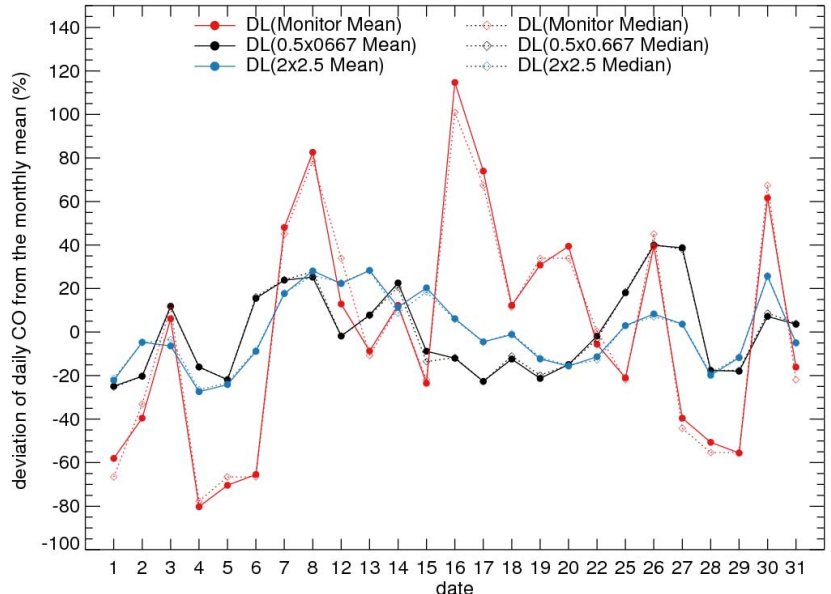

(d) Wind speed for 14:00 at DL sites for July 2005.

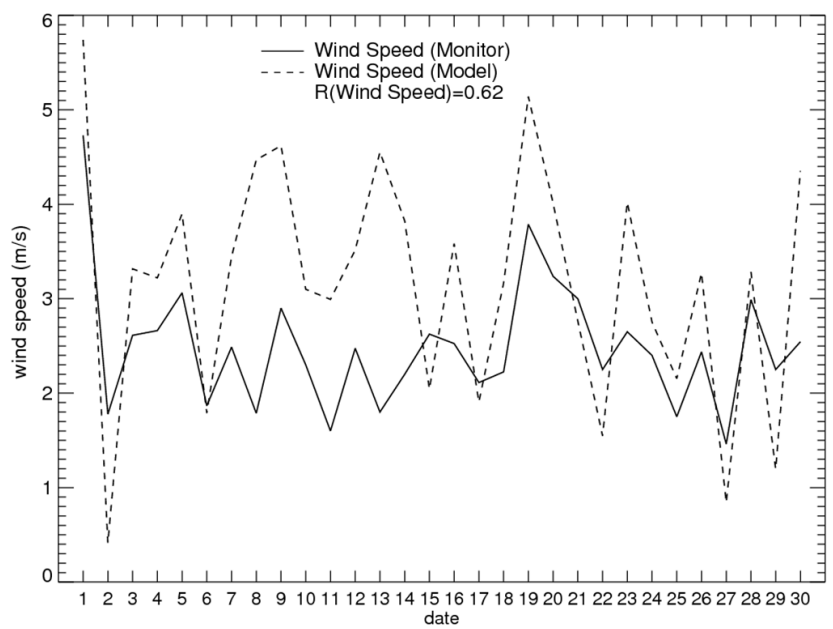

Fig. 6. Time series of CO concentration, wind speed, temperature, and pressure. Monitored and modeled in Beijing for July 2005.

and the suburban DL grid), TH (Tianjin-Hebei), SH (Shandong and parts of Hebei,), SX (Shanxi and Shaanxi,), SC (South China), and West China. In addition, emissions from India and South Asia were also tagged as they make important contributions to Asian outflow of CO to the NW Pacific as discussed in the next section. The tagged regions of emissions are indicated in Fig. 7. Detailed methodology of the tagged CO simulation was described in Wang et al. (2004a).

Table 2 summarizes the percentage contributions of individual $\mathrm{CO}$ tracers to total $\mathrm{CO}$ simulated at the DL site for each month. Emissions from the two Beijing grids (i.e. the urban grid and the suburban DL grid, denoted as BJ in the table) were referred to as local emissions in our study, while emissions from all the other tagged Chinese regions were regarded as regional emissions. We found that local emissions make up an average about $46 \%$ of $\mathrm{CO}$ mixing ratios at the DL site in summer. The regional emissions from the tagged Tianjin-Hebei region make up the second largest contribution, accounting for an average of $17 \%$ for CO at DL. The temporal correlation between the tagged BJ tracer (representing local emissions) and the $\mathrm{TH}$ tracer is 0.52 . The tagged SH tracer was also found to correlate well with the BJ tracer, although the contribution from the $\mathrm{SH}$ tracer is much smaller.

For air quality regulators, an important question is how to reduce pollutant concentrations on days with bad air quality. On those days, the relative contributions from local and regional emissions may differ from their mean contributions. Therefore, we now turn our attention to the contributions of tagged tracers on individual days. Figure 8 presents the dayto-day variations in mixing ratios of individual tagged tracers for July 2005. In all days, the BJ tracer makes the biggest 


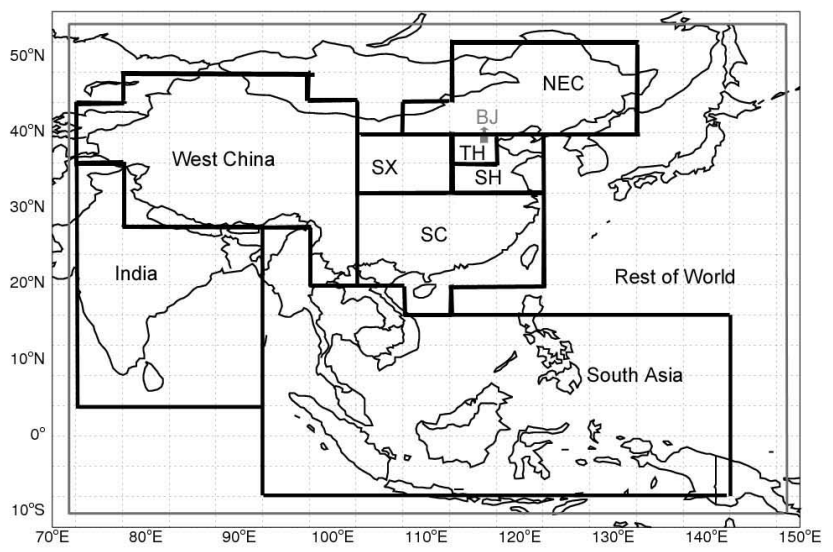

Fig. 7. Schematic representation of regional GEOS-Chem domains and source regions for tagged $\mathrm{CO}$ simulation. Regional domains are defined by the outermost thin gray lines, and the thick gray line is the actual boundary of the nested model. The grid boxes outside the gray rectangle in the fine-resolution domain define the buffer zone for boundary conditions.

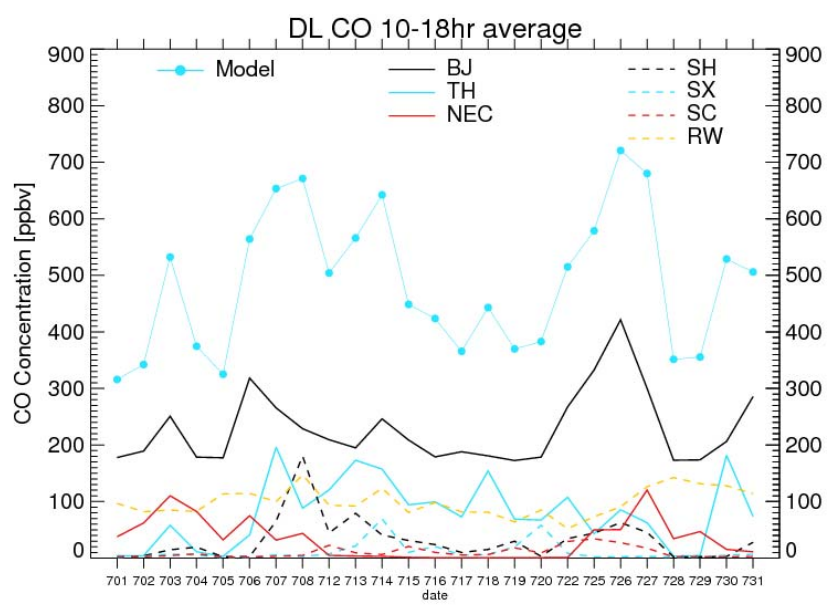

Fig. 8. Time series of daily contributions from tagged regions for July 2005 (unit: ppbv). (Blue solid line is the modeled total daily CO concentration at DL sites. Black, blue, and red solid lines are contributions from Beijing (BJ), Tianjin \& Hebei (TH), and Northeastern China (NEC). The dashed lines are for the other tagged regions, Shandong and Hebei (SH, black dashed), Shanxi and Shaanxi (SX, blue dashed), South China (red dashed), and Rest of World (yellow dashed)).

contribution, but its relative importance becomes smaller on high pollution days with high mixing ratios of $\mathrm{CO}$. For example, during the high pollution period between 6 July and 8 July, the BJ tracer accounted for only $35 \%-40 \%$ of the total $\mathrm{CO}$, while the influence from regional emissions was much higher, with the TH tracer and the SH tracer accounting for about $35 \%$ and $20 \%$, respectively, during the period. On relatively clean days (5 July and 28-29 July), the BJ tracer $(70-75 \%)$ and the global background made the biggest con-
Table 2. Modeled percentage contributions of emissions from different tagged regions to CO levels at DL site (\%).

\begin{tabular}{lcccc}
\hline Tagged Region & Jul & Aug & Sep & $\begin{array}{c}\text { Summer } \\
\text { Average }\end{array}$ \\
\hline Beijing (BJ) & 35.4 & 49.9 & 50.3 & 46.2 \\
Tianjin-Hebei (TH) & 20.0 & 15.8 & 16.8 & 17.3 \\
Shandong \& Hebei (SH) & 9.9 & 1.8 & 3.4 & 4.5 \\
Shanxi \& Shaanxi (SX) & 1.8 & 2.2 & 1.2 & 1.7 \\
Northeastern China (NEC) & 8.3 & 11.9 & 11.0 & 10.6 \\
South China (SC) & 3.3 & 0.7 & 0.3 & 1.2 \\
All the other regions combined & 22.4 & 18.8 & 18.4 & 19.6 \\
\hline
\end{tabular}

tributions. The tagged $\mathrm{CO}$ simulation indicates that during periods of heavy pollution the Beijing, Tianjin-Hebei, Shandong, and Hebei regions were particularly important source regions.

\subsection{Meteorological conditions}

To investigate the meteorological conditions controlling the differences between heavily polluted and relatively clean days in summer, we chose 2-4 July as a representative period. The mixing ratios of $\mathrm{CO}$ observed at the DL site were relatively low on 2 July, rose to a high level on the second day and peaked on 3 July, followed by a rapid drop on 4 July. During this period of 3 days, the observed variations in $\mathrm{CO}$ mixing ratios differed by about a factor of three. The model reproduced well the sequence of variations, although it failed to reproduce the exact magnitude of the very high and very low mixing ratios of $\mathrm{CO}$ on 3 July and 4 July, respectively.

Figure 9 displays the distribution of winds and $\mathrm{CO}$ mixing ratios in the boundary layer as simulated by the model for each of the four days. From 2 July to 4 July, under the high pressure system over the East China Sea (the Pacific High), surface wind patterns indicate a strong maritime influence from southeast and central China with a general southeast onshore flow along the coast. On 2 July, a weak low-pressure system was centered over Mongolia, northwest of Beijing. The Beijing area was not strongly influenced by either the low-pressure system to the northwest or the high-pressure system to the southeast. A weak high-pressure system was located over the North China Plain, and the atmosphere was relatively static over Beijing on 2 July, with surface wind speeds below $1 \mathrm{~m} / \mathrm{s}$. The static conditions favored accumulation of the regional $\mathrm{CO}$ emissions from the heavily polluted Tianjin-Hebei area and local Beijing emissions, resulting in rapid rises in $\mathrm{CO}$ mixing ratios. Then on 3 July the flow switched to southwesterly flow in advance of the front bringing in regional pollution. The low-pressure system strengthened on 3 and 4 July and moved toward the southeast. By 4 July, the low-pressure center was to the east of Beijing, 

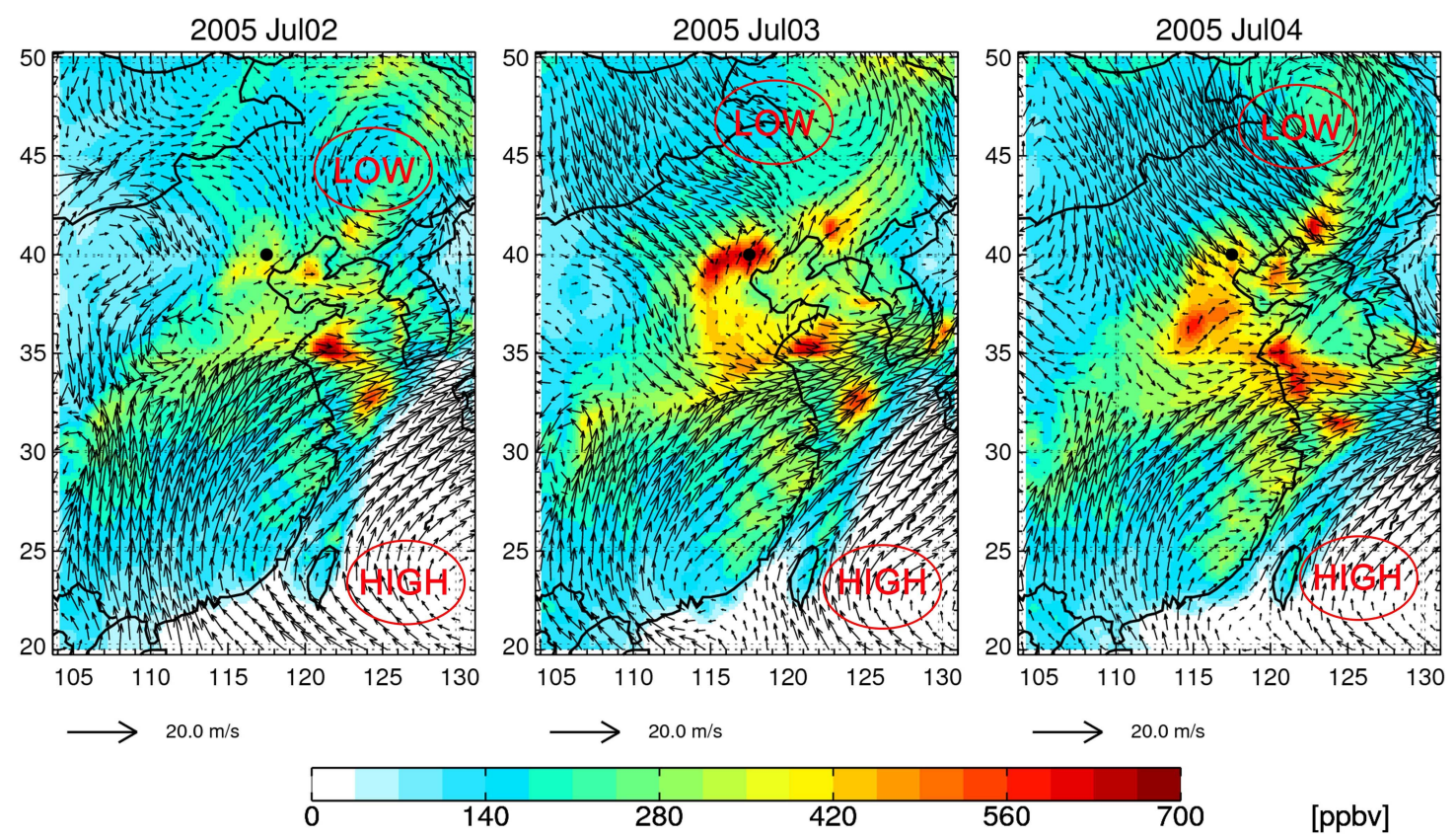

Fig. 9. Surface wind vectors and CO concentrations for the period of 2-4 July 2005.

with the associated strong northwesterly winds bringing relatively clean air to Beijing with CO levels over Beijing dropping accordingly. The meteorological setting for 2 to 4 July is consistent with the general description of the sawtooth cycles of $\mathrm{PM}_{2.5}$ levels over Beijing, as reported by Jia et al. (2008). They suggested that the passage of synoptic systems from the north is the key meteorological mechanism resulting in the dilution and removal of pollution from Beijing.

\section{China outflow}

The monsoonal circulation over East Asia is characterized by a general outflow of surface air from the continent in winter compensated by a maritime inflow in summer. Many previous studies have used $\mathrm{CO}$ as a tracer to examine the patterns and mechanisms of Asian outflow to the Pacific, and much of the attention has thus far been paid to springtime (Liu et al., 2003; Fuelburg et al., 2003; Liang et al., 2004, 2005, 2007; Miyazaki et al., 2003; Koile et al., 2003; Holzer et al., 2005). They found that the major process responsible for the export of Asian anthropogenic pollution to the western Pacific during spring is frontal lifting to the free troposphere (FT) ahead of southeastward-moving cold fronts and transport in the boundary layer (BL) behind the cold front. Orographic lifting over central and eastern China combines with the cold fronts to promote the transport of Chinese pollution to the FT. Liang et al. (2004) and Holzer et al. (2005) studied the seasonal variations of Asian outflow by using continuous $\mathrm{CO}$ measurements at a coastal site in Washington state and GEOS-Chem model. Liang et al. (2004) found maximum export of Asian pollution to the western Pacific occurs at $20^{\circ}-50^{\circ} \mathrm{N}$ during spring throughout the tropospheric column, shifting to $30^{\circ}-60^{\circ} \mathrm{N}$ during summer, mostly in the upper troposphere. They also developed three new sealevel pressure indices, which capture variations in transpacific transport on daily to inter-annual timescales and found that during summer, the Asian outflow displayed lower levels of $\mathrm{CO}$ due to shorter lifetime of $\mathrm{CO}$ in summer. Convective injection into the upper troposphere occurs predominantly in summer, as compared to the frontal mechanisms dominated in spring in the export (Liang et al., 2005, 2007). In this section, the outflow pattern in summertime is discussed and compared with that in spring. The analysis focuses on $\mathrm{CO}$ emitted from the geographical regions in Asia as defined in the tagged CO simulation described above (cf. Fig. 7). The domain adopted to evaluate the export fluxes is defined by $80^{\circ}-140^{\circ} \mathrm{E}$ longitude, $10^{\circ}-50^{\circ} \mathrm{N}$ latitude, and $0-12 \mathrm{~km}$ altitude. The regions of $\mathrm{SH}, \mathrm{TH}$, and $\mathrm{BJ}$ are combined here into the North China (NC) region.

Figure 10 presents the monthly (March-September 2005) mean fluxes of $\mathrm{CO}$ through the eastern $\left(140^{\circ} \mathrm{E}\right)$ boundary. The CO fluxes displayed in the figure are partitioned among three source regions, namely India, Southeast Asia, and East China (the aggregation of NC, SC, NEC, and SX). The geographical definition of these regions is shown in Fig. 7. The fluxes through the eastern boundary are positive (eastward) for each month. The overall fluxes in springtime are larger by a factor of 2-3 than the fluxes in summertime, consistent with the seasonality suggested by Liu et al. (2003) and Liang 


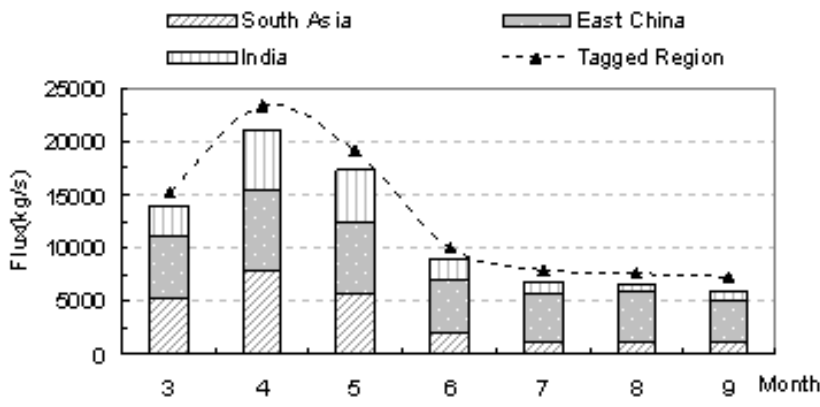

Fig. 10. Export fluxes of $\mathrm{CO}$ at $140^{\circ} \mathrm{E}$ contributed by emissions from different source regions. The domain adopted to evaluate the export fluxes is defined as $80^{\circ}-14^{\circ} \mathrm{E}$ longitude, $10^{\circ}-50^{\circ} \mathrm{N}$ latitude, and $0-12 \mathrm{~km}$ altitude. East China refers to the combination of $\mathrm{SH}$, TH, BJ, SC, NEC, and SX, (cf. Fig. 7).

Table 3. Export efficiencies of CO for tagged regions.

\begin{tabular}{ccccccc}
\hline & \multicolumn{3}{c}{ Spring (MAM) } & \multicolumn{3}{c}{ Summer (JJA) } \\
& E-W & N-S & Total & E-W & N-S & Total \\
\hline NC (SH \& TH \& BJ) & 0.36 & 0.09 & 0.45 & 0.48 & 0.18 & 0.66 \\
SX & 0.49 & 0.02 & 0.51 & 0.70 & 0.19 & 0.89 \\
NEC & 0.40 & 0.19 & 0.59 & 0.53 & 0.25 & 0.78 \\
SC & 0.58 & 0.07 & 0.65 & 0.75 & 0.13 & 0.88 \\
\hline
\end{tabular}

et al. (2004) for the export of Asian anthropogenic CO to the NW Pacific. CO originating from India and Southeast Asia accounts for about $60 \%$ of the total fluxes in spring. The fraction from these sources drops to $30 \%$ in summer. Seasonal biomass burning over India and Southeast Asia is responsible for the large export of $\mathrm{CO}$ from the two regions in spring. The seasonal variability in outflow from East China is relatively small, with summertime outflow only $30 \%$ lower than that in springtime. Emissions of $\mathrm{CO}$ from East China are responsible for about $40 \%$ of the total outflow of $\mathrm{CO}$ from Asia in spring, with the fraction increasing to $70 \%-80 \%$ in summer.

Table 3 summarizes the export efficiency of $\mathrm{CO}$ emitted from the tagged source regions in springtime (MAM) and summertime (JJA). The export efficiency of CO, evaluated separately for the north-south (northward as positive) and east-west (eastward as positive) directions, is defined as the ratio of the net export through the lateral boundaries to the total emissions from the source region. From the table, we can see that in both seasons the major export pathway is in the EW direction for all source regions. It has been suggested in many previous studies that $\mathrm{CO}$ emitted over Asia is transferred eastward through a two-step process (Liu et al., 2003; Wang et al., 2004; Fuelburg et al., 2003; Liang et al., 2004). First, it is lifted through vertical motions of the atmosphere (e.g. by fronts or convection) from the near-surface regions to higher altitudes. Subsequently, it is captured by strong westerlies that prevail in the free troposphere. Among the regions listed in Table 3, SC has the highest EW export efficiency because its location in the lower latitude with abundant solar radiation is conducive to stronger vertical motions of the lower atmosphere, resulting in efficient lifting of $\mathrm{CO}$ to the free troposphere. NEC has the highest NS export efficiency because of its location near the northern boundary. The EW export efficiency is higher in summer and so is the efficiency for NS export. The total export efficiency ranges from 0.45 (NC) to 0.65 (SC) in spring and from 0.66 (NC) to 0.89 (SX) in summer. The deeper convection in summer bringing $\mathrm{CO}$ to higher altitudes with more efficient export is the important factor for higher export efficiency in summer.

Miyazaki et al. (2003) and Koike et al. (2003) studied the export of anthropogenic reactive nitrogen and sulfur compounds from the East Asia region and the synoptic-scale transport mechanisms of the two chemical species over the western pacific in spring. Specifically, they calculated quantitatively the export efficiency of $\mathrm{NO}_{y}$ and $\mathrm{SO}_{x}$ using the $\mathrm{P}-$ $3 \mathrm{~B}$ and DC-8 aircraft observation data over the western Pacific during the TRACE-P campaign. Their results showed that $20-40 \%$ and $15 \%$ of $\mathrm{NO}_{x}$ emitted over the northeastern part of China remained as $\mathrm{NO}_{y}$ at $0-2 \mathrm{~km}$ (boundary layer) and $2-7 \mathrm{~km}$ (free troposphere), respectively. In the free troposphere, PAN was found to be the dominant form, while only $0.5 \%$ of emitted $\mathrm{NO}_{x}$ remained as $\mathrm{NO}_{x}$. The transport efficiency of $\mathrm{SO}_{x}$ was estimated to be $25-45 \%$ and $15-20 \%$ in the boundary layer and free troposphere, respectively. The results obtained in their study indicate that more than half of $\mathrm{NO}_{y}$ and $\mathrm{SO}_{x}$ were lost over the continent and that the vertical transport from the boundary layer to the free troposphere further reduced their amounts by a factor of 2 . The present study calculated the outflow of $\mathrm{CO}$ from different areas of China. Due to the longer lifetime associated with simple chemical loss and less efficient deposition of $\mathrm{CO}$ as compared to $\mathrm{NO}_{y}$ or $\mathrm{SO}_{x}$, the export efficiency of $\mathrm{CO}$ in spring calculated here is relatively higher than that for $\mathrm{NO}_{y}$ and $\mathrm{SO}_{x}$ reported by Miyazaki et al. (2003) and Koike et al. (2003).

Figure 11 presents latitude-altitude cross sections at $140^{\circ} \mathrm{E}$ of seasonal mean fluxes from the tagged East China regions for spring (MAM) (upper panels) and summer (JJA) (lower panels) 2005. Compared with springtime, summertime outflow from all the tagged Chinese source regions is strongest at higher latitudes (north of $35^{\circ} \mathrm{N}$ ). Inflow (i.e. negative fluxes) prevails through the whole troposphere south of $25^{\circ} \mathrm{N}$ in summer. This suggests that in summer, $\mathrm{CO}$ emitted from the surface is first transported northward by maritime inflow associated with the summer monsoon before being lifted to the free troposphere by deep convection and carried eastward by the strong westerlies. Northward transport is most significant for $\mathrm{CO}$ from $\mathrm{SC}$, for which emissions are from south of $30^{\circ} \mathrm{N}$, whereas outflow is confined to north of $35^{\circ} \mathrm{N}$. Consistent to the seasonality study of Asian export carried out by Liang et al. $(2004,2005,2007)$, the convection 
(a) SH \& TH \& BJ (MAM)
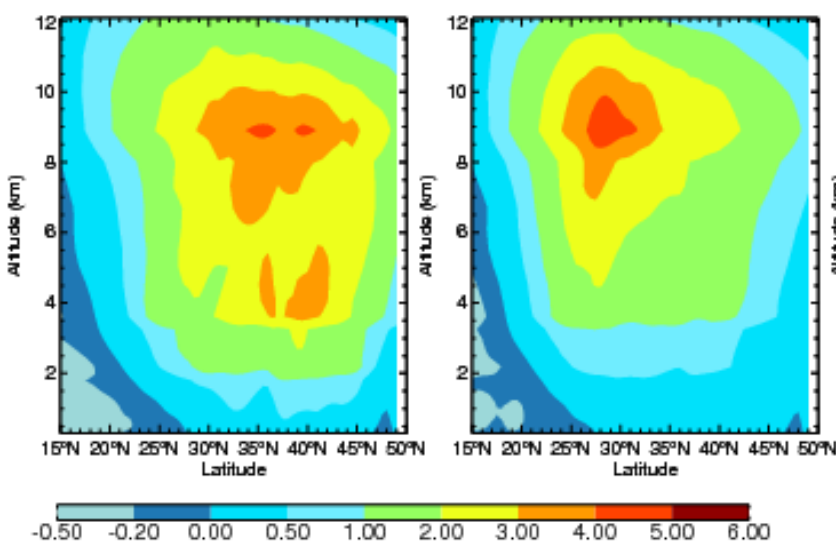

(e) SH \& TH \& BJ (JJA)

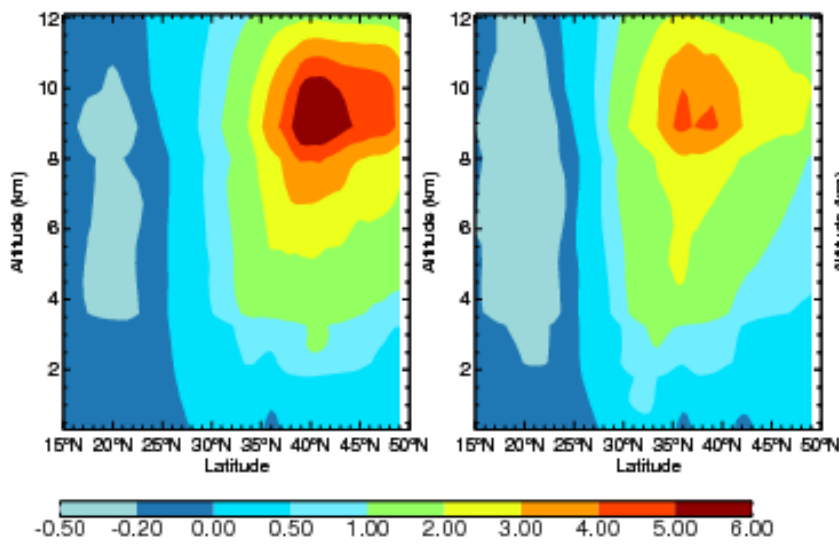

(c) SX (MAM)

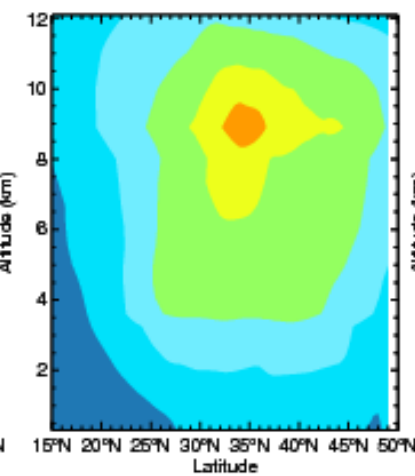

Latitude

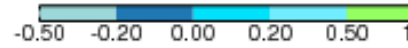

(g) $\mathrm{SX}$ (JJA)

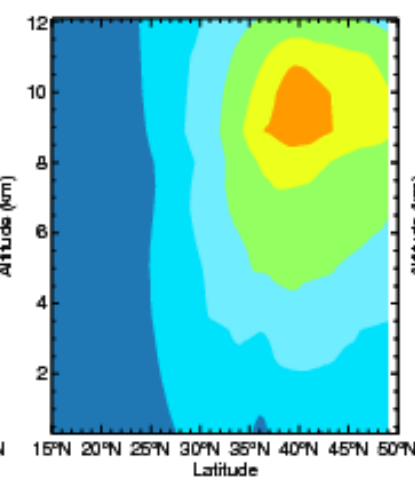

Latitude (d) NEC (MAM)

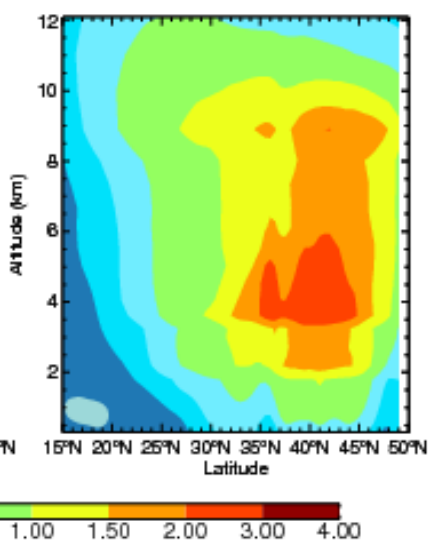

$[\mathrm{kg} / \mathrm{s}]$

(h) NEC (JJA)

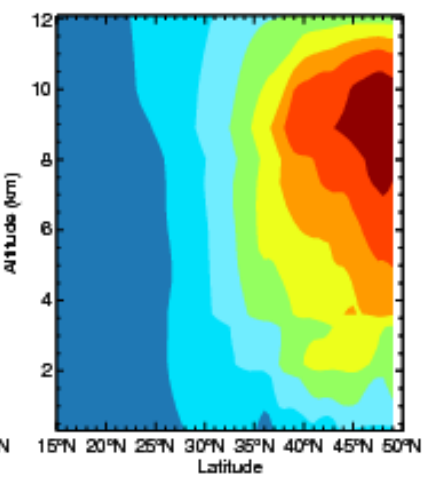

Latitude

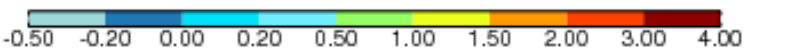

Fig. 11. Latitude-altitude cross sections at $140^{\circ} \mathrm{E}$ of seasonal mean fluxes of tagged CO tracers for spring (MAM) and summer (JJA) 2005 .

is expected to be stronger in summer than in spring, resulting in more efficient lifting and subsequently, stronger outflow in the free troposphere. In summer, the eastward fluxes of Chinese $\mathrm{CO}$ all take the common pathway confined to north of $35^{\circ} \mathrm{N}$ in the free troposphere, regardless of the latitudes from which emissions originated. In contrast, outflow in springtime is strongest over the same latitudes of emissions. For example, outflow from $\mathrm{SC}$ in springtime is strongest at $25^{\circ} \mathrm{N}$, while that from $\mathrm{NC}$ is strongest at $40^{\circ} \mathrm{N}$.

\section{Concluding remarks}

The updated fine-resolution $\left(0.5^{\circ} \times 0.667^{\circ}\right)$ nested-grid GEOS-Chem model developed here allows for better representation of the heterogeneity in emissions and transport compared with the coarse- and intermediate-resolution global models and the original nested-grid GEOS-Chem model at $1^{\circ} \times 1^{\circ}$ resolution (Wang et al., 2004a). Boundary conditions for the fine-resolution nested-grid model are provided by results from the coarse global model. Emis- sions over China in the fine-resolution model show patterns of fossil fuel and biofuel combustion spatially differentiated by economic development, industry structure, and population. The nested-grid simulation suggests that the highest $\mathrm{CO}$ column density over East Asia in summertime is at the Sichuan Basin, a feature not captured by the global model due to resolution limitations. Influenced by the East Asian summer monsoon, the Sichuan Basin is a favorable location for low-level stationary vortices (the southwest vortex) in summer that tend to trap pollutants over the Basin, resulting in elevated levels of CO. By comparing surface CO simulated at different model resolutions for the Beijing-TianjinHebei city clusters, we found that the fine-resolution nestedgrid model is capable of resolving individual cities with high emission intensities. These localized emissions would be smeared out over a coarse grid in the global models, leading to underestimates of $\mathrm{CO}$ mixing ratio at suburban sites.

The nested-grid model was used to analyze the day-to-day variations in $\mathrm{CO}$ at a suburban site near Beijing in summertime. The model was found to reproduce well the observed 
variations in temperature and surface pressure but was found to overestimate wind speeds. Since the suburban site is under the strong influence of Beijing urban emissions, overestimates in wind speeds by the model result in more rapid dilution and greater export of local emissions out of the grid, leading to underestimates of $\mathrm{CO}$ mixing ratios of the model. Tagged CO simulation results suggest that regional emissions from Tianjin, Shandong, and Hebei make significant contributions to elevated levels of $\mathrm{CO}$ over Beijing on polluted days. During these days, as much as $50 \%$ of $\mathrm{CO}$ in Beijing was associated with emissions from the three regions. We found that the southeastward moving cyclones that bring northwest winds to Beijing are the key meteorological mechanism responsible for dispersion of pollution over Beijing in summer.

The overall fluxes of $\mathrm{CO}$ to the NW Pacific from Asia are found to decrease by a factor of 3-4 from spring to summer, consistent with the seasonality suggested by other studies (Liu et al., 2004). Much of this reduction is driven by decreasing fluxes transported from India and Southeast Asia in summer. CO originating in India and Southeast Asia accounts for about $60 \%$ of the total fluxes in spring. The fluxes from East China are only 30\% lower in summer than in spring. Emissions from East China contribute about $40 \%$ of the total outflow of $\mathrm{CO}$ from Asia in spring, increasing to 70$80 \%$ in summer. We found that the major export pathway for Asian $\mathrm{CO}$ is in the EW direction in both spring and summer. Compared with springtime, summertime outflow from all the tagged Chinese source regions is strongest at higher latitudes (north of $35^{\circ} \mathrm{N}$ ). This suggests that in summer, $\mathrm{CO}$ emitted from the surface is transported first northward by maritime inflow associated with the summer monsoon before being lifted to the free troposphere by deep convections and carried eastward by the strong westerlies. The export efficiency of $\mathrm{CO}$ is greater in summer than in spring. The deeper convection in summer bringing $\mathrm{CO}$ to higher altitudes with more efficient export is the important factor for higher export efficiency in summer. The analysis suggests that despite the maritime inflow at lower latitudes in summer, summertime outflow of $\mathrm{CO}$ from East Asia, which takes the pathway more north and toward higher altitudes, is important for the global atmosphere.

Acknowledgements. The work of K. He and D. Chen was supported by the National High Technology Research and Development Program of China (Grant No. 2006AA06A305) and China's National Basic Research Program (2005CB422201). Y. Wang and M. B. McElroy were supported by the National Science Foundation, Grant ATM-0635548. D. Chen thanks the Harvard China Project for generously hosting her visit in 2007 and 2008, when the majority of her work was conducted. We thank D. G. Streets and Q. Zhang for providing the emission inventory data. We also thank C. Nielsen, J. Lin, and X. Lu for helpful discussions.

Edited by: B. N. Duncan

\section{References}

An, J., Li, X., Wang, Y., Shi, L., Hu, F., and Xu, Y.: Measurements of Atmospheric Boundary Layer $\mathrm{O}_{3}, \mathrm{NO}_{x}$ and $\mathrm{CO}$ in Summer with Beijing $325 \mathrm{~m}$ Meteorological Tower, Environm. Sci., 24(6), 43-47, 2003.

Bey, I., Jacob, D. J., Yantosca, R. M., Logan, J. A., Field, B., Fiore, A. M., Li, Q., Liu, H., Mickley, L. J., and Schultz, M.: Global modeling of tropospheric chemistry with assimilated meteorology: Model description and evaluation, J. Geophys. Res., 106, 23073-23096, 2001.

Cai, X., Zhang, R., Song, Yu., and Xie, S.: An Analysis on Background Concentration of PM10 and $\mathrm{SO}_{2}$ over Beijing Area, Clim. Environm. Res., 9(3), 445-453, 2004.

Chang, C., Yia, L., and Chen, G.: Numerical Simulation of Vortex Development during the 1992 East Asian Summer Monsoon Onset Using the Navy's Regional Model, Mon. Weather Rev., 128(6), 1604-1631, 2000.

Chen, D., Li, Y., and Huang R.: The physical process analyses of the southwest vortex development and its effect on heavy rainfall in Eastern Sichuan under the saddle pattern background of largescale circulations, Chinese J. Atmos. Sci., 31(2), 185-201, 2007

DAO: Algorithm Theoretical Basis Document for Goddard Earth Observing System Data Assimilation System (GEOS DAS) with a focus on version 2, http://dao.gsfc.nasa.gov/subpages/atbd. html, 1996.

Duncan, B., Martin, R., Staudt, A., Yevich, R., and Logan, J.: Interannual and Seasonal Variability of Biomass Burning Emissions Constrained by Satellite Observations, J. Geophys. Res., 108(D2), 4040, doi:10.1029/2002JD002378, 2003.

Fiore, A., Horowitz, L., Purves, D., Levy II, H., Evans, M., Wang, Y., Li, Q., and Yantosca, R.: Evaluating the contribution of changes in isoprene emissions to surface ozone trends over the eastern United States, J. Geophys. Res., 110, D12303, doi:10.1029/2004JD005485, 2005.

Fuelberg, H., Kiley, C., Hannan, J., Westberg, D., Avery, M., and Newell, R.: Meteorological conditions and transport pathways during the Transport and Chemical Evolution over the Pacific (TRACE-P) experiment, J. Geophys. Res., 108(D20), 8782, doi:10.1029/2002JD003092, 2003.

Holzer, M., Hall, T., and Stull, R.: Seasonality and weatherdriven variability of transpacific transport, J. Geophys. Res., 110, D23103, doi:10.1029/2005JD006261, 2005.

Jia, Y., Rahn, K., He, K., Wen, T., and Wang, Y.: A novel technique for quantifying the regional component of urban aerosol solely from its sawtooth cycles, J. Geophys. Res., 113, D21309, doi:10.1029/2008JD010389, 2008.

Koile, M., Kondo, Y., Kita, N., et al.: Export of anthropogenic reactive nitrogen and sulfur compounds from the East Asia region in spring, J. Geophys. Res., 108(D20), 8789, doi:10.1029/2002JD003284, 2003.

Koster, R., Suárez, M., Ducharne, A., Stieglitz, M., and Kumar, P.: A catchment-based approach to modeling land surface processes in a GCM, Part 1, Model Structure, J. Geophys. Res., 105, 24809-24822, 2000.

Li, Q., Jacob, D., Park, R., Wang, Y., Heald, C., Hudman, R., Yantosca, R., Martin, R., and Evans, M.: North American pollution outflow and the trapping of convectively lifted pollution by upper-level anticyclone, J. Geophys. Res., 110, D10301, doi:10.1029/2004JD005039, 2005. 
Liang, Q., Jaeglé, L., Jaffe, D., Weiss-Penzias, P., Heckman, A., and Snow, J.: Long-range transport of Asian pollution to the northeast Pacific: Seasonal variations and transport pathways of carbon monoxide, J. Geophys. Res., 109, D23S07, doi:10.1029/2003JD004402, 2004.

Liang, Q., Jaeglé, L., and Wallace, J.: Meteorological indices for Asian outflow and transpacific transport on daily to interannual timescales, J.Geophys. Res., 110, D18308, doi:10.1029/2005JD005788, 2005.

Liang, Q., Jaeglé, L., Hudman, R., et al.: Summertime influence of Asian pollution in the free troposphere over North America, J. Geophys. Res., 112, D12S11, doi:10.1029/2006JD007919, 2007.

Liu, H., Jacob, D., Bey, I., Yantosca, R., Duncan, B., and Sachse, G.: Transport pathways for Asian pollution outflow over the Pacific: Interannual and seasonal variations, J. Geophys. Res., 108, 8786, doi:10.1029/2002JD003102, 2003.

Miyazaki, Y., Kondo, Y., Koike, M., et al.: Synoptic-scale transport of reactive nitrogen over the western Pacific in spring, J. Geophys. Res., 108(D20), 8788, doi:10.1029/2002JD003248, 2003.

Park, R., Jacob, D., Kumar, N., and Yantosca, R.: Regional visibility statistics in the United States: Natural and transboundary pollution influences, and implications for the Regional Haze Rule, Atmos. Environ., 40(28), 5405-5423, 2006.

Rienecker, M., Suarez, M., Todling, R., Bacmeister, J., Takacs, L., Liu, H., Gu, W., Sienkiewicz, M., Koster, R., Gelaro, R., Stajner, I., and Nielsen, E.: The GEOS-5 Data Assimilation System Documentation of Versions 5.0.1, 5.1.0, and 5.2.0, NASA/TM2007-104606, vol. 27, edited by: Suarez, M. J..

Seinfeld, J. and Pandis S.: Atmospheric Chemistry and Physics: From Air Pollution to Climate Change, John Wiley, Hoboken, N. J., 1998.

Song, C., Byun, D., Pierce, R., Alsaadi, J., Schaack, T., and Vukovich, F.: Downscale linkage of global model output for regional chemical transport modeling: Method and general performance, J. Geophys. Res., 113, D08308, doi:10.1029/2007JD008951, 2008.

Stieglitz, M., Ducharne, A., Koster, R. D., and Suarez, M. J.: The impact of detailed snow physics on the simulation of snow cover and subsurface thermodynamics at continental scales, J. Hydrometeorol., 2, 228-242, 2001.
Streets, D., Bond, T., Carmichael, G., et al.: An inventory of gaseous and primary aerosol emissions in Asia in the year 2000, J. Geophys. Res., 108(D21), 8809, doi:10.1029/2002JD003093, 2003.

Streets, D., Zhang, Q., Wang, L., He, K., Hao, J., Wu, Y., Tang, Y., and Carmichael, G.: Revisiting China's CO emissions after the Transport and Chemical Evolution over the Pacific (TRACE-P) mission: Synthesis of inventories, atmospheric modeling, and observations, J. Geophys. Res., 111, D14306, doi:10.1029/2006JD007118, 2006.

Sun, Y., Wang, Y., Liu, G., An, J., Ma, Z., Shi, L., and Xu, H.: Analysis for Vertical Profile of Atmospheric $\mathrm{SO}_{2}$ During Air Seriously Polluted Days in Beijing, Environm. Sci., 27(3), 408414, 2006.

Wang, Y., McElroy, M., Jacob, D., and Yantosca, R.: A nested grid formulation for chemical transport over Asia: Applications to CO, J. Geophys. Res., 109, D22307, doi:10.1029/2004JD005237, 2004a.

Wang, Y., McElroy, M., Wang, T., and Palmer, P.: Asian emissions of $\mathrm{CO}$ and $\mathrm{NO}_{x}$ : constraints from aircraft and Chinese station data, J. Geophys. Res., 109, D24304, doi:10.1029/2004JD005250, 2004b.

Xia, H.: The Characteristics of Temperature inversion of the urban area in Beijing and its influence on the atmosphere pollution, China Academic Journal Electronic Publishing House, 6(2), 6366, 2004.

Yevich, R. and Logan, J.: An assessment of biofuel use and burning of agricultural waste in the developing world, Global Biogeochem. Cycles, 17(4), 1095, doi:10.1029/2002GB001952, 2003.

You, C., Cai, X., Song, Y., and Guo, H.: Local Atmospheric Circulations over Beijing-Tianjin Area in Summer, Acta Scientiarum Naturalium Universitatis Pekinensis, 42(6), 779-783, 2006.

Zhang, Q., Streets, D. G., Carmichael, G. R., He, K., Huo, H., Kannari, A., Klimont, Z., Park, I., Reddy, S., Fu, J. S., Chen, D., Duan, L., Lei, Y., Wang, L., and Yao, Z.: Asian emissions in 2006 for the NASA INTEX-B mission, Atmos. Chem. Phys. Discuss., 9, 4081-4139, 2009, http://www.atmos-chem-phys-discuss.net/9/4081/2009/. 